\title{
The Behavioral Correlates of Overall and Distinctive Life History Strategy
}

\author{
Ryne A. Sherman \\ Florida Atlantic University
}

\author{
Aurelio José Figueredo \\ University of Arizona
}

\author{
David C. Funder \\ University of California, Riverside
}

\begin{abstract}
Life history (LH) theory provides an evolutionary theoretical framework for understanding individual differences in maturation, mating, reproduction, parenting, and social interaction. However, the psychometric assessment of human life history has been largely limited to generalized self-reports. Using template matching, this article examines the relationship between personality differences associated with slow-life history (slow-LH) and social behavior in 3 archival datasets. Two of these datasets include direct observations of behavior in the laboratory, and the 3rd provides self-reports of behavior in real life situations experienced within the preceding $24 \mathrm{hr}$. The results paint a consistent picture of the slow-LH individual as engaging in numerous adaptive social behaviors. However, when "normativeness" (the tendency for most people to be normal in both the statistical and evaluative sense) is statistically removed from the LH scores, a slightly different picture emerges. Both slow-LH and fast-LH persons display a number of behaviors that may be either adaptive or maladaptive in different contexts. Specifically, slow-LH individuals tended to behave in a manner that was considerate, kind, hard-working, and reliable but also socially awkward, insecure, and overcontrolling. Fast-LH individuals came across as talkative, socially skilled, dominant, and charming but also unpredictable, hostile, manipulative, and impulsive. These results are consistent with the evolutionary interpretation of LH strategies as being adapted to systematically different environments rather than better or worse approaches to reproductive fitness overall.
\end{abstract}

Keywords: K-factor, mating strategies, life history, personality

Supplemental materials: http://dx.doi.org/10.1037/a0033772.supp

Different species follow different routes to survival (MacArthur \& Wilson, 1967; Pianka, 1970). Rabbits reach sexual maturity quickly, have numerous offspring, and offer only limited parental investment in each one, which leads to high infant mortality rates. Elephants reach sexual maturity only slowly, have few offspring, and make a high parental investment in each one, which leads to relatively low infant mortality

This article was published Online First August 5, 2013.

Ryne A. Sherman, Department of Psychology, Florida Atlantic University; Aurelio José Figueredo, Department of Psychology, University of Arizona; David C. Funder, Department of Psychology, University of California, Riverside.

This research was supported by National Institute of Mental Health Grant MH-42427 to David C. Funder, principal investigator (Studies 1 and 2) and National Science Foundation Grant BNS BCS-0642243 to David C. Funder, principal investigator (Study 3). Any opinions, findings, conclusions, or recommendations expressed in this article are those of the individual researchers and do not necessarily reflect the views of the National Institute of Mental Health or the National Science Foundation. All statistical analyses were conducted using R (R Core Team, 2013). Data files and $\mathrm{R}$ scripts for replicating the analyses reported here are available for download as supplemental material.

Correspondence concerning this article should be addressed to Ryne A. Sherman, Department of Psychology, Florida Atlantic University, 777 Glades Road, Boca Raton, FL 33431. E-mail: rsherm13@fau.edu rates (Figueredo, Sefcek, et al., 2005; Figueredo, Vásquez, et al., 2005). These different reproductive strategies have been characterized as fast and slow life history strategies, although these were previously better known as $r$-selected and K-selected strategies, respectively, due to an early emphasis on the influence of population densities as a major determinant (see Reznick, Bryant, \& Bashey, 2002). Contemporary life history (LH) theory represents an evolutionary-economic theory of the optimal allocation of bioenergetic and material resources among different components of fitness, constituting both (a) a descriptive theory of dimensionality, in which the various life history tradeoffs are organized into coordinated and internally coherent life history strategies and (b) a stochastic optimality theory of evolutionary dynamics, in which the evolutionary pressures selecting among different coadapted life history strategies are modeled. LH tradeoffs are the component tactical elements that are coadapted by selection into coordinated $\mathrm{LH}$ strategies. Examples of LH tradeoffs might include (a) parental survival versus current reproduction; (b) parental growth versus current reproduction; (c) current versus future reproduction; (d) current versus future offspring quantity; (e) current versus future offspring quality; and (f) current offspring quantity versus quality. Because LH strategies represent coevolved, coordinated patterns of optimal resource allocation that follow internally consistent and synergistic functional patterns, they 
are empirically discriminable as positive manifolds among the component LH traits (describing the tradeoffs actually made) that can be modeled as latent multivariate constructs, such as the $K$-Factor.

Thus, the dimension conceptualized as LH "speed," owing to the theoretical and empirical relationships between LH strategy and the rates of maturation, reproduction, and longevity (Figueredo, Vásquez, Brumbach, \& Schneider, 2004, 2007), ranges between two opposite ends of a continuum: an extremely fast ( $r$-selected) LH strategy would involve behaviors that lead to many offspring but put less energy into caring for each, whereas an extremely slow ( $K$-selected) strategy would involve behaviors that produce few (or perhaps only one) offspring but put more energy into the care and protection of each. Contemporary evolutionary ecology has largely abandoned the early emphasis on densitydependent factors in LH evolution. Instead, faster LH strategies are more adaptive in unstable, unpredictable, and uncontrollable environments, where the ability to reproduce quickly is crucial because life spans are short, whereas slower LH strategies are more adaptive in more regular, stable, and controllable environments and are associated with longer life spans (Ellis, Figueredo, Brumbah, \& Schlomer, 2009).

Relative to many other species, humans are said to generally tend more toward the slower LH end of this continuum, but substantial individual differences in LH speed have been documented in numerous species of plants and animals, including humans (e.g., Gladden, Sisco, \& Figueredo, 2008; Rushton, 1985, 2000). LH strategies manifest heritable variation (Figueredo et al., 2004; Rowe, 2000), and a single common $K$-Factor underlies a number of life history markers including sexual, reproductive, and parental behaviors (Figueredo, Sefcek, et al., 2005; Figueredo, Vásquez, et al., 2005). This K-Factor has been found to be positively associated with important outcomes including a combination of physical and mental health, including subjective well-being, called "covitality" (Figueredo et al., 2007), as well as relationship satisfaction (Olderbak \& Figueredo, 2010), such that slow-LH (high K) individuals are more likely to be physically and mentally healthy and to enjoy more satisfying relationships. Further, this $\mathrm{K}$-Factor is negatively associated with other outcomes that are generally considered less socially desirable, such as criminality (Rowe, Vazsonyi, \& Figueredo, 1997), delinquency (Charles \& Egan, 2005), sexual coercion (Gladden et al., 2008), and relationship dissolution (Olderbak \& Figueredo, 2010). According to several studies, fast-LH (low K) individuals are more likely to commit crimes, coerce others into sexual activity, and have relationships that end quickly. However, LH strategies do not appear to be related to psychopathic attitudes or intelligence (Gladden, Figueredo, \& Jacobs, 2009).

These findings seem theoretically coherent, but more research on individual differences in life history strategies remains needed. Figueredo, Sefcek, and colleagues (2005) concluded that "theory in evolutionary personality psychology is ahead of the data" and that "basic work must be done before the field matures enough to produce definitive accounts of the adaptive significance of personality differences" (p. 873). And while a few empirical studies advancing understanding of life history theory have been published since this conclusion, most research on LH, including the studies cited above, has been based exclusively or nearly exclusively on self-report. For example, studies linking K-Factor to criminality (Rowe et al., 1997) and sexual coercion (Gladden et al., 2008) relied entirely on self-report measures of the outcome variables. Even the study linking relationship satisfaction to K-Factor (Olderbak \& Figueredo, 2010) neglected to assess the partner's assessment of satisfaction. Self-reports are the easiest kind of data to gather and efficiently provide a great deal of information, so it is understandable that research in a new area would begin with this method. Over time, however, it becomes important for maturing areas of research to branch out into other methods for assessing constructs and associated outcomes (Baumeister, Vohs, \& Funder, 2007; Furr, 2009). A theoretical review of the history of measurement as applied to human LH strategy is currently in press (Figueredo, Cabeza de Baca, \& Woodley, 2013), and a metaanalytic validation of the psychometric approaches to measuring human LH strategy has just been completed (Figueredo, Wolf, Olderbak, et al., 2013).

\section{The Problem of Normativeness and Life History Theory}

In addition to this empirical limitation, the human LH literature may also suffer from a related conceptual issue. Figueredo and colleagues (2007) propose that a single "Super-K factor" (p. 60) explains the correlations between a large number of personality traits and social factors including relationship quality, social support, altruistic tendencies, financial status, persistence, planning, agency, communitarian beliefs, the Big Five personality traits, mental health, and physical health. The pattern of associations paints the portrait of the prototypical slow-life history person as including almost every socially desirable quality one could wish for, while the qualities of the prototypical fast-life history person are almost entirely socially undesirable. Such a view seems at odds with the broader biological conception of slow versus fast life history as being adaptations to different environments rather than globally "better" or "worse" strategies for reproductive success (Buss, 2009). From an evolutionary point of view, the endurance of fast-life history strategy as an alternative followed by an appreciable portion of individuals implies that there must be some adaptive behavioral patterns associated with this lifestyle within certain ecological contexts that are recurrent over evolutionary time.

Modern multilevel selection theory, however, distinguishes among evolutionary pressures that confer either benefits or costs to the individual and those that confer either benefits or costs to the social group. In almost all cases, it is evident that the behaviors that are generally classed as "socially undesirable" are those that inflict costs on others (meaning conspecific individuals) and not necessarily on the self (meaning the individual that performs them). Our social norms, and those of nearly every other organized human society, therefore tend to favor behaviors that are closer to characterizing the slower side of the LH continuum.

Normativeness is associated with better psychological adjustment (Baird, Le, \& Lucas, 2006; Borkenau \& Zaltauskas, 2009; Edwards, 1957; Fleeson \& Wilt, 2010; Klimstra, Luyckx, Hale, Goossens, \& Meeus, 2010; Sherman, Nave, \& Funder, 2012; Wood, Gosling, \& Potter, 2007; Wood \& Wortman, 2012). Thus, when examining the associations among traits and outcomes such as those mentioned in the previous discussion, the theoretical underpinnings of slow-life history are naturally confounded with 
being "normal" in both the statistical and the evaluative sense, meaning that they tend to follow the prevailing social norms. ${ }^{1}$ Moreover, the high correlation between the two senses of normative behavior leads to the conflation of statistical normality with evaluative normality. This is likely because social norms evolve to differentially reinforce behaviors that confer benefits and costs to the social group. Because social norms must be enforced by these rewards or punishments to be maintained, individual behavior is shaped by these contingencies such that the individual self-interest may become partially aligned with the group interest by these social control mechanisms: This is very likely how the normativeness of the behaviors in the evaluative sense functions to produce the normativeness of the behaviors in the statistical sense. Obviously, shaping the behavior of others to be prosocial must be beneficial to the rule-enforcers of these norms to be selected, given that they reap some of the benefits (although an element of altruism is involved in that some of the benefits accrue to others as well); learning these prosocial patterns of behavior consequently becomes adaptive for the prospective rule-followers because of the social contingencies set up by the rule-enforcers. It is also quite possible that slow LH strategists are overrepresented among the rule-enforcers (those who formulate and promulgate social norms in any society; see Cabeza De Baca \& Jordan, 2012; Woodley, 2010), given that (a) slow life history strategists are more socially concerned and socially engaged (being high-investment individuals), and (b) slow life history strategists may, by virtue of their prosocial behaviors, rise higher in the social hierarchy than faster LH strategists, and thus acquire the social power and influence to enforce these norms. Of course, these social regulatory mechanisms do not always work and are most likely to fail in social environments that are unstable, unpredictable, and uncontrollable because they destabilize the social contingencies. These are precisely the conditions that lead to the evolution and development of faster life histories, which are less mutualistic and more antagonistic in character.

If this is indeed the case, we would expect to find that when measures of LH are adjusted for normativeness, both fast and slow life history persons should display a mix of both adaptive and maladaptive social qualities, when assessing benefits and costs at the individual level of selective advantage or disadvantage. These ideas on the complex multilevel selective pressures acting jointly on prosocial and antisocial traits are considered in greater detail in a recent monograph on historical variability in human intelligence (Woodley \& Figueredo, 2013).

\section{The Current Research}

The present research seeks to answer two basic questions: (a) How do fast versus slow life history people behave in various social contexts? (b) Does normativeness conflate the picture of how slow versus fast life history people behave? Because of psychology's overreliance on self-report, directly observed behavior is rarely measured (Baumeister et al., 2007; Furr, 2009). One reason is that measuring directly observed behavior is timeconsuming and expensive. Therefore, to address the questions just posed, we draw on previously gathered datasets from three large scale research projects: the Riverside Accuracy Project-Phase I (RAP-I), the Riverside Accuracy Project-Phase II (RAP-II), and the Riverside Situation Project (RSP). The first two datasets in- clude direct behavioral observations; the third data set includes retrospective self-reports of behaviors performed less than $24 \mathrm{hr}$ earlier. More details about each of these datasets are provided later.

\section{Measuring Life History}

None of these datasets was specifically designed to measure life history. However, participants in all three conditions completed the California Adult Q-Set (CAQ: Block, 1961/1978) as modified for nonprofessional use by Bem and Funder, 1978. The modified CAQ contains 100 diverse personality characteristics designed to broadly cover the personality domain (e.g., "Is genuinely dependable and responsible"; "Is guileful and deceitful, manipulative, opportunistic"; Bem \& Funder, 1978). When completing a Q-sort of the CAQ (as in RAP-I and RSP datasets), participants rate their own personalities by sorting each of the 100 characteristics into one of nine categories $(1=$ extremely uncharacteristic, 9 = extremely characteristic) forming a forced-choice, quasi-normal distribution. When completing a Q-rate of the CAQ (as was done in RAP-II) participants rate each of the 100 characteristics as it pertains to them using the same 9 categories in a Likert-type format. LH scores can be generated from the CAQ through template matching.

The template matching technique (see Bem \& Funder, 1978) entails correlating (matching) an observed pattern of personality characteristics with a theoretically derived pattern. For the purposes of this research, a theoretical template for the slow- $L H$ personality was created by averaging independent Q-sort ratings provided by six experts on life history theory, who used the CAQ to describe the prototypical slow-LH person. ${ }^{2}$ These expert ratings manifested an average intercorrelation of $r=.58$, resulting in a reliability for the composite of the six ratings of .89 . The three modified CAQ (Bem \& Funder, 1978) items marking the high end of this slow-LH template were "Is a genuinely dependable and responsible person," "Has warmth; has the capacity for close relationships; compassionate," and "Is protective of those close to him or her." The three modified CAQ items marking the low end of this template (i.e., fast-LH) were "Is unpredictable and changeable in behavior and attitudes," "Is guileful and deceitful, manip-

\footnotetext{
${ }^{1}$ This argument is intended to apply to the "average" individual and does not apply to social deviants. Social deviants are by definition a minority in any population, and in this view they are kept that way by the costs in fitness associated with the social norms that they violate. However, they are never entirely eliminated, either due to the imperfect enforcement of these norms (as by inefficient detection of rule breaking) or due to the presumably compensating benefits of rule breaking (in that proportion of cases where the "crime" might indeed pay!). Even so, this phenomenon does not invalidate the analyses employed herein where the average person is of course sensitive to the proportion of the population that is socially deviant (Figueredo \& Jacobs, 2010).

${ }^{2} \mathrm{We}$ are grateful to the members of the Ethology and Evolutionary Psychology (EEP) Laboratory of the University of Arizona for performing these ratings. Individual participants included Pedro Sofio Abril Wolf, Paul Robert Gladden, Zachary Hohman, W. Jack Jacobs, Dawn Hill, Tomás Cabeza de Baca, and Candace Jasmine Black. Because of a computer scoring error, only six of the seven ratings could be used to create the template.
} 
ulative, opportunistic," and "Tends to be rebellious and nonconforming." 3

To quantify the degree to which a person scores high or low on slow-LH, his or her scores on the 100-item CAQ can be correlated with this theoretical template. Such template match scores have theoretical limits of -1.00 and $+1.00 .^{4}$ However, and as we suspected, in the three datasets we examine here, this theoretical slow-LH template was positively associated with the normative (mean) self-reported CAQ profile $r=.62, r=.61$, and $r=.60$ in the RAP-I, RAP-II, and RSP datasets, respectively. Such a relationship between the average CAQ profile and the slow-LH template is not surprising as previous research has demonstrated that slow-LH (or K-factor) is associated with covitality-a composite measure of physical and psychological well-being (Figueredo et al., 2007)—and previous research has demonstrated that the average personality profile is associated with psychological adjustment (Baird et al., 2006; Borkenau \& Zaltauskas, 2009; Edwards, 1957; Fleeson \& Wilt, 2010; Klimstra et al., 2010; Sherman et al., 2012; Wood et al., 2007; Wood \& Wortman, 2012).

Such high associations between the theoretical slow-LH template and the average personality profile raise two analytic concerns (Furr, 2008). First, the expert raters who described the prototypical slow-LH person using the CAQ had no direct knowledge of the average (normative) CAQ profile of the participants in our sample. Yet, a participant's slow-LH score would be considerably affected by the degree to which he or she matches this average. A second, deeper concern is that, as already mentioned, slow-LH is theoretically conceived as a lifestyle that is adapted to some environments and possibly not to others, yet the high correlation between the slow-LH score and statistical normality also leads it to be conflated with overall adaptive normality for the average individual, as described above.

To respond to these concerns, we computed slow-LH template match scores in two ways. The first way, referred to as "overall slow-LH," simply correlated the original theoretical slow-LH template with each participant's personality profile. The second way, referred to as "distinctive slow-LH," was done by correlating the theoretical slow-LH template with each participant's personality profile after statistically removing the association between normativeness and the slow-LH template (i.e., each participant's CAQ profile was regressed onto the mean CAQ profile and the residual CAQ profiles were then correlated with the slow-LH template). Descriptive statistics for these two template match scores are provided in the results section for each study; however, it is worth noting here that the distinctive template match scores were highly correlated with the overall slow-LH template match scores with $r$ s of .70, .77, and .74 for RAP-I, RAP-II, and RSP, respectively.

Despite the high correlations between the overall slow-LH scores and the distinctive slow-LH scores, they are not identical. As an illustration, an ad hoc measure of psychological adjustment constructed in each dataset was more strongly correlated with overall slow-LH scores ( $r$ s of $.39, .43$, and .31 for RAP-I, RAP-II, and RSP, respectively) than with distinctive slow-LH scores ( $r$ s of $.03, .04$, and -.10 within each of the same datasets). ${ }^{5}$ To assess the difference between the constructs measured by overall and distinctive slow-LH scores, the three studies reported in this article examine the correlations between social behavior and both.

\section{Study 1: RAP-I}

The RAP-I dataset was collected from October of 1990 through June of 1993 and was designed to identify and understand mechanisms involved in accurate personality judgment. It includes a large battery of self-reported personality measures, peer reports of personality, real time mood data using beepers, and behavioral data from as many as seven different interactions. Of particular importance for the present project, this dataset includes selfreported personality information from 220 undergraduate participants and directly observed behavior of these participants in three 5 min dyadic interactions. Because of the richness of this dataset it has yielded many publications (e.g., Blackman \& Funder, 1996, 1998; Creed \& Funder, 1998a, 1998b; Eaton \& Funder, 2001; Funder, Kolar, \& Blackman, 1995; Furr \& Funder, 1998, 2004; Kashdan, Sherman, Yarbro, \& Funder, in press; Markey, Funder, \& Ozer, 2003; Schimmack, Oishi, Furr, \& Funder, 2004; Sneed, McCrae, \& Funder, 1998; Spain, Eaton, \& Funder, 2000); however, the analyses reported here are novel.

\section{Participants}

Participants were recruited via campus fliers and paid $\$ 5$ per hour. From an original sample of 220 undergraduate participants, 175 ( 88 female, 87 male) provided complete data on the 100 item CAQ. Their mean age was 19.58 years $(S D=1.69$; age data not reported for 27 participants). The $N$ s for each analysis may be slightly lower than 175 due to missing data on other measures. Participants missing any data were removed prior to analysis.

\section{Measures}

California Adult Q-Set. See the Measuring Life History section for a description of the CAQ.

Riverside Behavioral Q-Set (Version 2.0). The Riverside Behavioral Q-Set Version 2.0 (RBQ: Funder, Furr, \& Colvin, 2000) consisted of 64 behavioral items (e.g., "Dominates interaction," "Expresses agreement frequently") designed to measure social behavior in video-recorded laboratory experimental settings.

\section{Procedure}

Behavioral interactions. Participants in this study were videotaped in a series of interpersonal interactions, including three 5-min interactions with an opposite sex stranger (who was also another participant). In the first (unstructured) interaction, partic-

\footnotetext{
${ }^{3}$ The full template for all $100 \mathrm{CAQ}$ items is available as a supplemental table at http://psy2.fau.edu/ shermanr/Pubs.html/LifeHistory Supplement.zip

${ }^{4}$ It should be noted that life history is considered a bipolar measure, with slow-life history forming one pole while fast-life history forms the other Throughout this article we refer to these match scores as "slow-LH" scores to indicate the direction of the positive pole; readers should be aware that low scores on slow-LH indicate high scores on fast-LH.

${ }^{5}$ The measure of psychological adjustment was an aggregate of selfreported scores on neuroticism (reverse-scored), depression (reversescored), ego-resiliency, subjective well-being, and psychological wellbeing, with the actual measures used sometimes differing by study. An example of such a measure used is described by Sherman and colleagues (2012), and specific information about how this construct was formed in each study may be obtained from the first author.
} 
ipants were told they could talk about whatever they wanted for the next $5 \mathrm{~min}$. In the second (cooperative) interaction, participants were given a set of Tinkertoys and instructed to work together to build a particular model. In the third (competitive) interaction, participants played the memory game Simon; the winner of three out of five games received an extra dollar.
Behavioral coding. For each of these three interactions, four independent coders viewed the videotaped interaction and completed an RBQ (using the Q-sorting procedure) describing each participant's behavior. No coder rated a participant in more than one of the three interactions, to avoid potential Rater $\times$ Target confounds. Because this archival dataset only contains the com-

Table 1

Behavioral Correlates of Overall and Distinctive Self-Rated Slow-Life History in RAP-I

\begin{tabular}{|c|c|c|c|c|c|c|}
\hline \multirow[b]{3}{*}{ RBQ item } & \multicolumn{6}{|c|}{ Interaction condition } \\
\hline & \multicolumn{2}{|c|}{ Unstructured } & \multicolumn{2}{|c|}{ Cooperative } & \multicolumn{2}{|c|}{ Competitive } \\
\hline & Overall & Dist. & Overall & Dist. & Overall & Dist. \\
\hline \multicolumn{7}{|l|}{ Positive correlates (slow-life history) } \\
\hline 60. Engages in constant eye contact & $.34^{* * * * *}$ & $.18^{*}$ & & & & \\
\hline 04. Interested in what partner says & $.26^{* * * *}$ & $.16^{*}$ & & $.20^{*}$ & & \\
\hline 29. Seems likeable & $.23^{* *}$ & & & & $.16^{*}$ & $.13^{\dagger}$ \\
\hline 50. Behaves in cheerful manner & $.22^{* * *}$ & & & & & \\
\hline 08. Exhibits social skills & $.21^{* *}$ & & & & $.19^{*}$ & \\
\hline 52. Behaves in stereotypical gender style & $.20^{*}$ & $.25^{* *}$ & & & & \\
\hline 25. Expresses sympathy towards partner & $.19^{*}$ & $.17^{*}$ & & & & $.14^{\dagger}$ \\
\hline 11. Smiles frequently & $.19^{*}$ & & & & & \\
\hline 30. Seeks advice from partner & $.18^{*}$ & $.28^{* * * *}$ & & $.16^{*}$ & & $.14^{\dagger}$ \\
\hline 43. Seems to enjoy interaction & $.17^{*}$ & & & & $.14^{\dagger}$ & \\
\hline 33. Expresses warmth & $.15^{*}$ & & & & & \\
\hline 13. Seems to like partner & $.15^{\dagger}$ & & & & $.17^{*}$ & $.14^{\dagger}$ \\
\hline 02. Interviews partner & $.15^{\dagger}$ & & & & & \\
\hline 37. Behaves in fearful or timid manner & $.14^{\dagger}$ & $.27^{* * *}$ & & $.29^{* * * *}$ & & $.15^{\dagger}$ \\
\hline 10. Laughs frequently & $.13^{\dagger}$ & & $.16^{*}$ & & & \\
\hline 22. Expresses Insecurity & & $.23^{* *}$ & & & & $.17^{*}$ \\
\hline 09. Reserved and unexpressive & & $.16^{*}$ & & $.24^{* * *}$ & & \\
\hline 27. Seeks reassurance from partner & & & $.23^{* * *}$ & $.25^{* * *}$ & & $.21^{* * *}$ \\
\hline 19. Expresses agreement frequently & & & $.15^{*}$ & $.28^{* * * *}$ & & \\
\hline 23. Physical signs of tension/anxiety & & & & $.23^{* * *}$ & & \\
\hline 14. Exhibits awkward interpersonal style & & & & $.21^{* * * *}$ & $-.13^{\dagger}$ & \\
\hline 41. Keeps partner at a distance & & & & $.17^{*}$ & & \\
\hline 45. Says negative things about self & & & & $.15^{\dagger}$ & & \\
\hline 59. Makes/approaches physical contact & & & & & $.16^{*}$ & \\
\hline 44. Says/does interesting things & & & & & $.15^{*}$ & \\
\hline 63. Acts playful & & & & & $.14^{\dagger}$ & \\
\hline \multicolumn{7}{|l|}{ Negative correlates (fast-life history) } \\
\hline 20. Expresses criticism & $-.26^{* * *}$ & $-.14^{\dagger}$ & & & $-.17^{*}$ & \\
\hline 57. Speaks in a loud voice & $-.22^{* *}$ & $-.23^{* *}$ & & $-.23^{* *}$ & & $-.18^{*}$ \\
\hline 05. Tries to control interaction & $-.21^{* * *}$ & $-.18^{*}$ & & & & $-.17^{*}$ \\
\hline 18. Talks at partner & $-.21^{* *}$ & & & & & \\
\hline 58. Speaks sarcastically & $-.19^{*}$ & $-.14^{\dagger}$ & & & & \\
\hline 28. Exhibits condescending behavior & $-.19^{*}$ & $-.14^{\dagger}$ & & & & \\
\hline 36. Unusual/unconventional appearance & $-.18^{*}$ & $-.18^{*}$ & & & & \\
\hline 32. Acts irritated & $-.18^{*}$ & & & & $-.14^{\dagger}$ & \\
\hline 35. Expresses hostility & $-.16^{*}$ & & & & & \\
\hline 39. Interest in fantasy or daydreams & $-.16^{*}$ & & & & & \\
\hline 55. Emphasizes accomplishments & $-.14^{\dagger}$ & & & & & \\
\hline 06. Dominates interaction & $-.14^{\dagger}$ & $-.14^{\dagger}$ & & & & $-.17^{*}$ \\
\hline 38. Expressive in voice, face, or gestures & & $-.16^{*}$ & $-.13^{\dagger}$ & $-.25^{* * *}$ & & \\
\hline 12. Physically animated; moves a lot & & $-.13^{\dagger}$ & $-.21^{* *}$ & $-.29^{\text {**** }}$ & & \\
\hline 62. Speaks quickly & & & $-.17^{*}$ & $-.15^{*}$ & & \\
\hline 16. High enthusiasm and energy level & & & & $-.24^{* *}$ & & \\
\hline 21. Is talkative & & & & $-.14^{\dagger}$ & $.14^{\dagger}$ & \\
\hline 24. Exhibits high degree of intelligence & & & & $-.13^{\dagger}$ & & \\
\hline 56. Competes with partner & & & & & & $-.20^{*}$ \\
\hline Average absolute $r$ & $.116^{* * * *}$ & $.099^{* *}$ & .060 & $.101^{* * *}$ & $.084^{\dagger}$ & .074 \\
\hline
\end{tabular}

Note. RBQ item content abbreviated. Unstructured $n=163$; cooperative $n=165$; competitive $n=162$. RAP-I $=$ Riverside Accuracy Project-Phase I; $\mathrm{RBQ}=$ Riverside Behavioral Q-Set Version 2.0; Dist. = distinctive.

${ }^{\dagger} p<.10 .{ }^{*} p<.05 .{ }^{* *} p<.01 .{ }^{* * * *} p<.001$. 
posite scores, we are unable to recalculate the reliability of these behavioral ratings. However, a previous publication reported the median item reliability to be .55 .

Personality measures. At two later sessions participants completed a large battery of personality questionnaires including (at one of those sessions) the CAQ, which is the measure of particular interest for this study.

\section{Results}

Overall and distinctive slow-LH scores were computed as previously described. The average overall slow-LH score was .36 $(S D=.20)$, indicating that on average people have personality trait patterns that better fit the prototypical slow-LH person than the prototypical fast-LH person. The average distinctive slow-LH score was $.00(S D=.13)$, which is a mathematically required value given that the average CAQ profile was statistically removed from the template. There were no sex differences in overall slow-LH scores (female $M=.38$, male $M=.34$ ) or distinctive slow-LH scores (female $M=.01$, male $M=.00$ ).

How do slow-life history people behave? The overall and distinctive slow-LH scores generated from self-reports of the CAQ were correlated separately with the composite ratings of directly observed behavior from the three $5 \mathrm{~min}$ interactions. The results are displayed in Table 1, with each pair of columns reporting the overall and distinctive slow-LH correlations with behavior for each of the three interaction conditions. Because 64 correlations were computed for each column, we protected against overinterpreting chance findings by employing a randomization test originally described by Block (1960) and advanced by Sherman and Funder (2009). Specifically, following the method described by Sherman and Funder, we calculated the average absolute correlation between slow-LH and the 64 items of the RBQ, which represents the degree to which the items of the RBQ are related to the slow-LH scores (the value in the last row of Table 1). Next, we randomly paired the observed slow-LH scores with the RBQ profiles and computed the average absolute correlation for this pseudo-dataset. We repeated this last step 1,000 times and retained the pseudo-average absolute correlation for each repetition to form a sampling distribution for the original observed average absolute correlation. We then compared our original observed value to this sampling distribution to obtain a $p$ value that represents the probability of observing our actual average absolute correlation if the data were randomly associated with participants. As the results in Table 1 show, the average absolute correlations between slow-LH and behavior yielded statistically significant tests at less than .10 for four out of the six columns in Table 1. This is one indication that the patterns of correlations in those columns were unlikely to have occurred by chance.

A closer examination of the results in Table 1 reveals that while the overall and distinctive columns for each interaction condition share some correlates, many only appear in one. This may come as a surprise given that the correlation between overall and distinctive slow-LH scores is $r=.70$ and the vector correlations between the overall and distinctive columns in Table 1 are $.68, .57$, and .48 for each of the three interaction conditions, respectively. But specific correlates are nonetheless different.

Consider the unstructured interaction. In that condition, overall slow-LH was positively associated with a bevy of positive behav- iors including seeming likeable, behaving cheerfully, exhibiting social skills, and smiling frequently. Overall slow-LH was negatively associated with negative behaviors including expressing criticism, talking at one's partner, acting irritated, and expressing hostility. However, this picture changes somewhat when the normativeness component of slow-LH is removed. Distinctive slow-LH was positively associated with behaving in a fearful or timid manner, expressing insecurity, and acting reserved and unexpressive. On the other hand, distinctive slow-LH was negatively associated with expressiveness and trying to control and dominate the interaction. Further, the negative associations between slow-LH and hostility and irritation do not emerge when normativeness is removed. This trend of different behavioral correlates with overall and distinctive slow-LH was also seen in the other two interaction settings. For example, in the competitive interaction overall slow-LH was positively associated with exhibiting social skills, enjoying the interaction, saying/doing interesting things, and acting playful and being talkative and negatively correlated with expressing criticism and acting irritated. However, these associations disappear when distinctive slow-LH is considered, the data instead painting a picture of the slow-LH person as sympathetic and likeable yet also insecure, fearful, and desiring advice and reassurance (quite interesting considering the competitive nature of the situation) while the distinctively fast-LH person is seen as loud, dominating, controlling, and competitive.

Sex differences. We examined all correlations in Table 1 separately for each sex. Because the patterns of correlations are less reliable (i.e., the sample sizes are smaller) we do not present the results here. However, interested readers can view them (along with full matrix of correlates for Table 1) by downloading the supplemental material (see supplemental material footnote 3 ). Those viewing such materials will note that there are both similarities and differences in the behavioral correlates of overall and distinctive slow-LH between the sexes. Further, these sex differences sometimes vary by interaction condition. We caution readers to resist the temptation to make strong inferences, however, because, as just noted, the sample sizes are considerably smaller.

\section{Discussion}

The results show an impressive array of behavioral correlates of slow-LH. Most interestingly, they paint strikingly different views of the slow (vs. fast) life history person depending on whether the overall or distinctive measure is used-even though overall and distinctive slow-LH scores are themselves highly correlated. If one considers only overall slow-LH scores, the results mirror the findings of previous research indicating that slow-LH people have many conventionally "positive" (meaning socially desirable) and very few conventionally "negative" (meaning socially undesirable) qualities (e.g., Figueredo et al., 2007). However, if one considers the distinctive slow-LH history scores, the results reveal how both slow-LH and fast-LH persons have adaptive strengths and weaknesses. For instance, persons scoring high on (adjusted) slow-LH were observed to act in a manner described as insecure, fearful, timid, anxious, unexpressive, and awkward. At the same time, these people were also observed to be sympathetic, interested in what their partner had to say, agreeable, and liking their partner. People scoring low on (adjusted) slow-LH (or high on fast-LH) were described as loud, domineering, critical, sarcastic, and con- 
descending. But they were also seen as enthusiastic, expressive, talkative, and socially skilled.

The next study attempts to replicate these findings using a different archival dataset that includes not only directly observed social behavior but also word usage during a life history interview.

\section{Study 2: RAP-II}

The RAP-II dataset was collected from the spring of 2000 through the spring of 2002 and was also designed to identify and understand the mechanisms involved in accurate personality judgment. This dataset includes a large battery of self-reported personality measures, peer reports of personality, clinician reports of personality, a life history ${ }^{6}$ interview with a trained clinician, and behavioral data from a three-person social interaction. In particular, it includes self-reported personality information from 304 undergraduate participants along with directly observed behavior from a three-person social interaction and word use frequencies for participants during a 1-hr life history interview. This dataset has also yielded many publications (e.g., Fast \& Funder, 2008, 2010; Fast, Reimer, \& Funder, 2008; Letzring, Block, \& Funder, 2005; Letzring, Wells, \& Funder, 2006; Naumann, Guillaume, \& Funder, 2012; Nave, Sherman, \& Funder, 2008; Vazire \& Funder, 2006; Wagerman \& Funder, 2007); however, the analyses reported here are novel.

\section{Participants}

Participants were recruited via campus fliers and were paid up to $\$ 100$ depending on the number of hours completed. From an original sample of 304 participants, 205 (92 female, 102 male, 11 not reported) provided complete scores on the 100 item CAQ. The mean age of these 205 participants was 20.52 years $(S D=2.83$; data not reported for 55 participants). The $N$ s for each analysis may be lower than 205 because of occasionally missing data. Participants missing data were removed prior to analysis.

\section{Measures}

The same California Adult Q-Set (CAQ) and the Riverside Behavioral Q-Set Version 2.0 (RBQ) as described previously were used in this study.

\section{Procedure}

Personality measures. Participants completed as many as three take home packets of personality surveys at different times throughout the course of their participation, the first of which included the CAQ using a 1 (extremely uncharacteristic) to 9 (extremely characteristic) Likert-type rating format.

Behavioral interactions. Participants were randomly assigned to one of five, three-person, interpersonal interaction conditions. Each three-person interaction was videotaped for later behavioral coding with the exception of the first conditionminimal interaction - because this condition served as a baseline and participants were instructed to make personality judgments of each other as soon as they arrived while keeping interaction to a minimum. The second (trivia) condition lasted for $50 \mathrm{~min}$, and participants were instructed to work together to complete a set of trivia questions. The third (short unstructured) condition lasted for
$50 \mathrm{~min}$, and participants were instructed to talk about whatever they would like. The fourth (get to know you; GTK) condition lasted $50 \mathrm{~min}$, and participants were instructed to get to know each other as well as possible. The fifth (long unstructured) condition lasted for $3 \mathrm{hr}$, and participants were instructed to talk about whatever they would like. Participants were given a short break halfway through this $3 \mathrm{hr}$ session.

Behavioral coding. For each of the videotaped interactions, four independent coders viewed the recording and completed an RBQ (using the Q-sorting procedure) describing each participant's behavior. As a means of quality control, codes were compared with those from other raters of the same participant, using intraclass correlations. A coding was retained if it agreed at least .30 with one other coding or at least .20 with two others. When these criteria were not met, the coding was discarded and an additional one was completed. Behavioral composites were formed by averaging the ratings on the $64 \mathrm{RBQ}$ items across the four coders. The average intraclass correlation (ICC) for a single rater across the 64 items was $.31(S D=.15)$, with an average reliability for the composite of $.61(S D=.17)$.

Life history interviews. Participants individually completed a 1-hr life history interview conducted by one of four clinically trained and licensed psychologists (e.g., master of social work, master of arts in counseling, or doctorate in clinical psychology) who had experience working with college student-age populations. Participants were told they would be questioned by a "professionally trained interviewer" to reduce any demand characteristics that might result from the knowledge they were seeing a clinical psychologist. The interviews were video recorded.

The clinicians conducted a semistructured interview adapted from a protocol developed by the Institute of Personality Assessment and Research (IPAR: Craik et al., 2002). The interview topics were adapted to better apply to college students and to capture a broad range of personality-relevant information without explicitly asking about sensitive topics or risky behaviors. All participants were asked the same questions in the same order. Interviews began by asking, "Tell me something about yourself." The topics then included academic experiences, future plans, interpersonal relationships, and childhood and family history. The interview concluded by asking the participant to "Describe a defining event in your life that had a significant impact on or changed your life in some way."

Quantifying and categorizing word use. Each life history interview was transcribed and analyzed separately (after deleting everything said by the interviewer) using the Linguistic Inquiry Word Count program (LIWC: Pennebaker, Francis, \& Booth, 2001). The LIWC analyzes language on a word-by-word basis. It includes a master dictionary of over 2,200 words and word stems, and these words are assigned to particular word categories. A total of 87 categories and linguistic elements (e.g., commas, periods, and question marks) can be analyzed using the LIWC. However, linguistic elements and some categories are difficult to translate from spoken language (e.g., commas, periods, nonfluencies such

\footnotetext{
${ }^{6}$ The term life history here refers to the design of the interview, in which the participant was asked about his or her life up to the present, and should not be confused with the psychological term life history, which is the topic of this article.
} 
Table 2

Behavioral Correlates of Overall and Distinctive Slow-Life History in RAP-II

\begin{tabular}{lcc}
\hline \multicolumn{1}{c}{ RBQ item } & Overall & Distinctive \\
\hline Positive correlates & & \\
55. Emphasizes accomplishments & $.23^{* * *}$ & \\
46. Displays ambition & $.22^{*}$ & \\
29. Seems likeable & $.17^{\dagger}$ & \\
25. Expresses sympathy towards partners & $.15^{\dagger}$ & $.18^{*}$ \\
09. Reserved and unexpressive & & $.25^{* *}$ \\
30. Seeks advice from partners & $.21^{*}$ \\
19. Expresses agreement frequently & $.19^{*}$ \\
14. Exhibits awkward interpersonal style & $.18^{*}$ \\
41. Keeps partners at a distance & $.18^{*}$ \\
61. Seems detached from interaction & $.16^{\dagger}$ \\
55. Emphasizes accomplishments & $.16^{\dagger}$ \\
37. Behaves in a fearful or timid manner & $.16^{\dagger}$ \\
\hline
\end{tabular}

Negative correlates

26. Initiates humor

01. Aware of being on camera

34. Tries to undermine/sabotage

58. Speaks sarcastically

57. Speaks in a loud voice

21. Is talkative

38. Expressive in voice, face, or gestures

44. Says/does interesting things

06. Dominates interaction

$\begin{array}{ll}-.25^{* * *} & -.34^{* * * * *} \\ -.24^{* * *} & -.18^{*} \\ -.21^{*} & \\ -.19^{*} & -.16^{\dagger} \\ & -.30^{* * * *} \\ & -.24^{* *} \\ & -.21^{*} \\ & -.17^{\dagger} \\ & -.17^{\dagger}\end{array}$

Average absolute $r$

.082

$103^{*}$

Note. Overall $n=129$; distinctive $n=129$. RBQ item content abbreviated. Vector correlation between overall and distinctive patterns is $r=.54$. RAP-II = Riverside Accuracy Project-Phase II; RBQ = Riverside Behavioral Q-Set Version 2.0.

${ }^{\dagger} p<.10 .{ }^{*} p<.05 .{ }^{* * *} p<.01 .{ }^{* * *} p<.001$.

as "um" and "huh"); thus, such categories were excluded from analysis. This left 69 word categories, including but not limited to total word count; positive and negative emotions; references to oneself, one's family, and others; swear words; sexual words; achievement oriented words; and words relating to work or occupations. On average, $72 \%(S D=6 \%)$ of the words spoken in the interviews fell into one of the LIWC categories, which is consistent with the $75 \%(S D=8 \%)$ found by Pennebaker and colleagues (2001) across 43 studies. For each participant, the total number of words used in each of these 69 categories was retained for analysis.

\section{Results}

Overall and distinctive slow-LH scores were computed as previously described. The average overall slow-LH score was .37 $(S D=.18)$, indicating that on average people have personality trait patterns that better fit the prototypical slow-LH person than the prototypical fast-LH person. The average distinctive slow-LH score was .01 $(S D=.13)$. There were no sex differences in overall slow-LH scores (female $M=.38$, male $M=.38$ ) or distinctive slow-LH scores (female $M=.01$, male $M=.01$ ).

How do slow-life history people behave? Table 2 displays the overall and distinctive slow-LH correlates of behavior from the video-recorded interactions in RAP-II. Although the tasks in the three-person interactions differed, we report the correlations with the behavior ignoring interaction condition because the $\mathrm{Ns}$ for each condition were small (i.e., 35-36), and thus, the patterns of correlations at the level of each condition must be considered unreliable. As in Study 1, sex differences in correlations are not shown. However, all of these correlations are available in the supplemental materials (see supplemental material footnote 3 ).

Similar to the analyses in Study 1, the results of a randomization test (see Sherman \& Funder, 2009) are displayed in the bottom row of Table 2. The average absolute correlation between overall slow-LH and behavior was .082, and the $p$ was .183, a level not greatly beyond chance. Indeed, the sheer number of statistically significant correlations between overall slow-LH and directly observed behavior in this study is low (6 out of 64). Further, the correlations between the overall slow-LH pattern in Table 2 and the three overall slow-LH patterns in Table 1 are $r=.24, .10$, and .29 (for Unstructured, Cooperative, and Competitive, respectively). This indicates that the overall slow-LH patterns are not

Table 3

Word Use Correlates of Overall and Distinctive Slow-Life History in RAP-II

\begin{tabular}{|c|c|c|}
\hline Word category (examples) & Overall & Distinctive \\
\hline \multicolumn{3}{|l|}{ Positive correlates } \\
\hline Six or more letter words & $.23^{* *}$ & $.17^{*}$ \\
\hline Numbers (one, thirty, million) & $.17^{*}$ & \\
\hline Fillers (you know, I mean) & & $.21^{* *}$ \\
\hline Occupation (work, class, boss) & & $.19^{*}$ \\
\hline Tentative (maybe, perhaps, guess) & & $.18^{*}$ \\
\hline School (class, student, college) & & $.16^{*}$ \\
\hline Achievement (try, goal, win) & & $.15^{\dagger}$ \\
\hline \multicolumn{3}{|l|}{ Negative correlates } \\
\hline Negative emotion (hate, worthless, enemy) & $-.33^{* * *}$ & $-.25^{* * *}$ \\
\hline Anger (hate, kill, pissed) & $-.23^{* *}$ & $-.17^{*}$ \\
\hline Physical states/functions (ache, breast, sleep) & $-.23^{* *}$ & $-.21^{* *}$ \\
\hline First person singular (I, my, me) & $-.23^{* *}$ & $-.15^{\dagger}$ \\
\hline First person (I, we, me) & $-.22^{* *}$ & $-.15^{\dagger}$ \\
\hline Sadness/depression (grief, cry, sad) & $-.21^{* *}$ & $-.19^{*}$ \\
\hline Family (mom, brother, cousin) & $-.19^{*}$ & $-.16^{*}$ \\
\hline Pronouns (I, our, they, you're) & $-.19^{*}$ & \\
\hline TV and movies (TV, sitcom, cinemas) & $-.18^{*}$ & \\
\hline Swear (damn, fuck, piss) & $-.18^{*}$ & $-.18^{*}$ \\
\hline Eating/drinking (eat, swallow, taste) & $-.17^{*}$ & \\
\hline Affect/emotion (happy, ugly, bitter) & $-.16^{*}$ & $-.22^{* *}$ \\
\hline Sex/sexuality (lust, penis, fuck) & $-.16^{*}$ & $-.16^{*}$ \\
\hline Sensory processes (see, touch, listen) & $-.16^{*}$ & \\
\hline Money/finances (cash, taxes, income) & $-.15^{\dagger}$ & \\
\hline Communication (talk, share, converse) & $-.15^{\dagger}$ & \\
\hline Hearing (heard, listen, sound) & $-.15^{\dagger}$ & \\
\hline Motion (walk, move, go) & $-.14^{\dagger}$ & \\
\hline Down (down, below, under) & $-.13^{\dagger}$ & \\
\hline Grooming (wash, bath, clean) & $-.13^{\dagger}$ & $-.14^{\dagger}$ \\
\hline Time (hour, day, o'clock) & $-.13^{\dagger}$ & \\
\hline Sleeping/dreaming (asleep, bed, dreams) & $-.13^{\dagger}$ & \\
\hline Home (house, kitchen, lawn) & $-.13^{\dagger}$ & \\
\hline Body states/symptoms (ache, heart, cough) & & $-.21^{* * *}$ \\
\hline Positive feelings (happy, joy, love) & & $-.16^{*}$ \\
\hline Death/dying (dead, burial, coffin) & & $-.15^{\dagger}$ \\
\hline Positive emotions (happy, pretty good) & & $-.13^{\dagger}$ \\
\hline Average absolute $r$ & $.104^{* *}$ & $.093^{* * *}$ \\
\hline
\end{tabular}

Note. Overall $n=164$; distinctive $n=164$. Word use is adjusted for total words used. Vector correlation between overall and distinctive patterns is $r=.85$. RAP-II $=$ Riverside Accuracy Project-Phase II.

${ }^{\dagger} p<.10 .{ }^{*} p<.05 .{ }^{* *} p<.01 .{ }^{* * *} p<.001$. 
very replicable across these two studies. Thus, we would caution against reading too much into the overall slow-LH behavioral correlates in Table 2.

The distinctive slow-LH correlates of behavior in Table 2 present quite a different story. First, the total number of statistically significant correlates and the average absolute association are less likely to be due to chance $(p=.043)$. Second, the correlations between distinctive slow-LH pattern in Table 2 and the distinctive slow-LH patterns in Table 1 are $r=.63, .72$, and .52. This indicates a more replicable behavioral pattern associated with distinctive slow-LH history. As can be seen in Table 2, persons scoring high on distinctive slow-LH were observed to express sympathy, to act reserved, to ask partners for advice, and to express agreement frequently, among other correlates. Fast-LH was associated with behavior described as talkative, humorous, loud, and dominating, among other correlates.

How do slow-life history people talk? Before investigating this question, it is important to elaborate a technical note about the word count analyses. The LIWC software (Pennebaker et al., 2001) returns raw word count frequencies. However, some participants spoke more words than others during their 1-hr life history interview $(M=7,345$ words, $S D=2,135, \min =2,305, \max =$ $15,918)$. Therefore, analyses conducted on raw word counts may be confounded with the sheer number of words spoken by that participant. To eliminate this confound, we first predicted the word-usage frequencies for the 68 remaining word categories from total words spoken and retained the residuals. These residuals represent the relative frequency of words used from each category, controlling for total words spoken. The relative frequencies are then used in the subsequent analyses. It is worth noting that overall slow-LH correlated $r=-.04$ with total words spoken and distinctive slow-LH correlated $r=-.12$ with total words spoken, indicating that slow-LH persons talked slightly less than fast-LH persons. Word count analysis thus provides various measures of verbal behavior but does not rely on self-report for its content and thus avoids its associated self-presentation biases.

The overall and distinctive slow-LH scores for each participant were correlated with the 68 word category (relative) frequencies. The results of this analysis appear in Table 3. As previously, a randomization test procedure was used to protect against capitalizing on chance, and the results appear in the last row of Table 3.

Table 3 shows a large number of word usage correlates of both overall and distinctive slow-LH. Although the correlation between the overall slow-LH and distinctive slow LH pattern shown in Table 3 is quite high $(r=.85)$, a few differences are worth highlighting. First, distinctive slow-LH was associated with using filler words (e.g., you know, I mean) and more tentative words (maybe, perhaps, guess). This suggests that distinctively slow-LH persons may be less confident or just prefer to temper their answers. Distinctively slow-LH persons also used more words related to work, school, and achievement and more words with six or more letters. As such words are infrequent in everyday speech (Pennebaker et al., 2001) this finding may indicate that slow-LH persons have broader vocabularies. Together, these findings paint a picture of the slow-LH person as more concerned with his or her career and being productive but, at the same time, agreeable and perhaps a bit uncertain.

Fast-LH persons, on the other hand, were more likely to use emotionally charged words (both positive and negative), to talk about themselves and other people, to swear more, and to use words related to sex, sexuality, death and dying. Combined with the slight connection between fast-LH and total words noted above, this pattern suggests that fast-LH people might be characterized as fast-talkers who expound on a wide variety of topics (excepting topics related to school and work). They are also more likely to use dramatic words or words with shock value.

\section{Discussion}

The results of this study show another impressive array of correlates of life history, particularly for distinctive slow-LH. The behavioral correlates, derived from different types of three-person interactions, were similar to the distinctive correlates in Study 1, which employed shorter, dyadic interactions. As in Study 1, persons scoring high or low on distinctive slow-LH show a blend of both positive and negative social behaviors. For instance, the behavior of those scoring high on distinctive slow-LH tended to be described as sympathetic, agreeable, relaxed, and interested in what their partner had to say and also as fearful, unexpressive, awkward, and visibly anxious. The behavior of those scoring low on distinctive slow-LH tended to be described as talkative, funny, expressive, enthusiastic, and socially skilled and, at the same time, loud, dominating, critical, and sarcastic.

In terms of overall slow-LH history, very few behavioral correlates emerged, and the results were not consistent with those found in Study 1. This is interesting because distinctive slow-LH, which had many associations, overlaps highly with overall slowLH. Further, by virtue of being a residualized score, the distinctive slow-LH scores are less reliable (i.e., the effect sizes are more greatly underestimated). Thus, the conflation between overall slow-LH and normativeness might mask associations between LH and behavior.

The unique contribution of this study was its examination of word use. Persons scoring higher on (distinctive) slow-LH tended to talk more about work and achievement and to use more fillers and tentative terms. These results suggest that slow-LH individuals are oriented toward achievement and success but somewhat unsure of their abilities. On the other hand, persons scoring low in slow-LH used many more emotion words of both the positive and negative variety, talked about themselves and about other people more, and used more words involving somewhat taboo areas such as sex, depression, death, and swearing. People scoring low on slow-LH may be more comfortable opening up to someone they just met and talking about themselves and their feelings.

The results of the two studies so far paint a mixed portrait of the slow-LH individual, when normativeness is removed, as generally kind, reliable, and hard-working, but at the same time socially awkward and fearful. The fast-LH individual, on the other hand, is seen as socially skilled, charming, fearless, unpredictable, and one who speaks his or her mind, even to a fault. However, the results remain limited because they derive from laboratory experiments where participants were assigned to interactions; they may lack generalizability to real world situations people encounter naturally. The next study moves to assessments of real-world behavior.

\section{Study 3: RSP}

Data for the Riverside Situation Project (RSP) were collected from the fall of 2007 through the spring of 2009. The project was 
designed to identify and measure psychologically important properties of situations. The dataset includes a large battery of selfreported personality measures, peer reports of personality, selfreports of properties of four different situations participants experienced in their daily lives, self-reports of behavior in those situations, and self-reports of how participants felt in those situations; it has yielded several publications so far (Sherman, Nave, \& Funder, 2010, 2012, 2013) and one doctoral dissertation (Sherman, 2011); however, the analyses here are novel. Of relevance to the present study, the dataset includes self-reported personality from 221 undergraduate participants and self-reported behavior from four situations experienced by these participants.

\section{Participants}

Participants were recruited via fliers on campus and an online psychology department participant recruiting system and were paid \$12.50 per hour with a maximum payment of \$75.00. From an original sample of 221 participants, 204 (105 female, 99 male) participants provided usable data for the present analyses. Their mean age was $19.62(S D=1.74)$ years. The ethnic breakdown is 8\% African American, 38\% Asian, 13\% Caucasian, 27\% Latino/ Hispanic, $13 \%$ other, and $1 \%$ No Response. The Ns for each analysis vary slightly because of occasional missing data. Participants missing data were removed prior to analysis.

\section{Measures}

The same California Adult Q-Set (CAQ) as described previously was used in this study. This study also employed a newer, 67-item version of the Riverside Behavioral Q-Set (Version 3.11) revised for use outside laboratory settings (Furr, Wagerman, \& Funder, 2010).

The Riverside Situational Q-Sort. The Riverside Situational Q-Sort (RSQ: Sherman et al., 2010; Wagerman \& Funder, 2009) Version 2.0 comprises 81 items describing psychological characteristics of situations (e.g., "Talking is permitted, invited, or conventionally expected," "Context is potentially anxiety inducing").

\section{Procedure}

Personality measures. During a preliminary visit to the laboratory, participants completed a large number of personality measures, including the CAQ using the Q-sort technique.

Behavioral reports. In the 4 weeks following the initial visit to the laboratory, each participant returned four more times (at least $48 \mathrm{hr}$ after any previous visit). During these visits, the participant was given a $3 \times 5$ in. index card and asked to write down what he or she was doing at one of four prespecified times within the previous $24 \mathrm{hr}$ (10 a.m., 2 p.m., 5 p.m., or 9 p.m.). A Latin-square design was used such that approximately $1 / 4$ th of the participants completed the study using each of the following time sequences across the four measurement occasions: 10 a.m.-2 p.m.-5 p.m.-9 p.m.; 2 p.m. -5 p.m.-9 p.m.-10 a.m.; 5 p.m.-9 p.m.-10 a.m.-2 p.m.; and 9 p.m. -10 a.m. -2 p.m. -5 p.m. Participants were instructed to only specify one situation and that if they were sleeping they should write down what they were doing right before they went to sleep or right after they woke up. The situations described by participants were typical of an undergraduate population (e.g., going to class, eating lunch with friends, at work); more detail is provided in the article by Sherman and colleagues (2010).

Later in the session participants completed an RBQ (using the Q-sort technique) describing their behavior in that situation. These RBQ ratings were averaged across the four reports to form a composite for each participant representing his or her average behavior across his or her four situations. Two participants only completed one behavioral rating, and one participant only completed two behavioral ratings. In such cases, only the usable behavioral ratings were used to make a composite. Among those with four behavioral ratings, the average ICC for a single rater across the $67 \mathrm{RBQ}$ items was $.19(S D=.07)$, with an average ICC for the composite of $.46(S D=.11)$.

Table 4

Behavioral Correlates of Overall and Distinctive Slow-Life History in RSP

\begin{tabular}{llc}
\hline \multicolumn{1}{c}{ RBQ item } & Overall & Distinctive \\
\hline Positive correlates & & \\
64. Concentrates; works hard at task & $.22^{* *}$ & $.21^{* *}$ \\
45. Displays ambition & $.21^{* *}$ & $.20^{* *}$ \\
52. Offers advice & $.20^{* *}$ & $.16^{*}$ \\
28. Seems likeable & $.20^{* *}$ & \\
41. Interested in intellectual/cognitive matters & $.19^{* *}$ & $.13^{\dagger}$ \\
24. Expresses sympathy & $.19^{* *}$ & \\
16. Displays a wide range of interests & $.18^{*}$ & $.12^{\dagger}$ \\
43. Says/does something interesting & $.17^{*}$ & \\
18. Expresses agreement frequently & $.16^{*}$ & $.16^{*}$ \\
65. Engages in physical activity & $.16^{*}$ & \\
06. Appears relaxed and comfortable & $.16^{*}$ & \\
12. Seems to like others & $.15^{*}$ & \\
63. Others seek advice from subject & $.15^{*}$ & \\
58. Makes/approaches physical contact & $.14^{*}$ & \\
03. Interested in what partner(s) say & $.13^{\dagger}$ & \\
36. Behaves in a fearful/timid manner & & $.15^{*}$ \\
24. Expresses sympathy & $.15^{*}$ \\
\hline
\end{tabular}

Negative correlates

27. Exhibits condescending

44. Says negative things about self

33. Tries to undermine/sabotage

34. Expresses hostility

35. Unusual or unconventional appearance

40. Keeps others at a distance

17. Talks at others

46. Blames others

21. Expresses insecurity

14. Compares self to others

57. Speaks sarcastically

$.15^{*}$

22. Shows physical signs of tension/anxiety

25. Initiates humor

20. Is talkative

48. Expresses sexual interest

38. Interest in fantasy or daydreams

30. Regards self as physically attractive

07. Exhibits social skills

\begin{tabular}{ll}
$-.31^{* * *}$ & $-.18^{*}$ \\
$-.26^{* * *}$ & \\
$-.23^{* * *}$ & \\
$-.18^{* * *}$ & $-.12^{\dagger}$ \\
$-.18^{* *}$ & $-.15^{*}$ \\
$-.18^{* *}$ & \\
$-.16^{*}$ & \\
$-.15^{*}$ & \\
$-.15^{*}$ & \\
$-.14^{*}$ & \\
$-.13^{\dagger}$ & \\
$-.12^{\dagger}$ & \\
& $-.21^{* *}$ \\
& $-.18^{*}$ \\
& $-.17^{*}$ \\
& $-.17^{*}$ \\
& $-.14^{*}$ \\
& $-.12^{\dagger}$ \\
\hline
\end{tabular}

Average absolute $r$

$.109^{* * * * *}$

$.085^{* *}$

Note. Overall $n=205$; distinctive $n=205$. Vector correlation between overall and distinctive patterns is $r=.61 \mathrm{RBQ}$ item content abbreviated $\mathrm{RBQ}=$ Riverside Behavioral Q-Set Version 2.0; RSP = Riverside Situation Project.

${ }^{\dagger} p<.10 .{ }^{*} p<.05 .{ }^{* *} p<.01 .{ }^{* * *} p<.001$. 
Third-party situation ratings. In an effort to quantify the psychological characteristics of the situations the participants experienced from a third-party consensual perspective, the descriptions on each $3 \times 5$ index card were independently read and rated by four research assistants (out of a pool of 22) using the RSQ. Raters used the Q-sort technique, and as a means of quality control the four ratings for each situation description were examined for profile agreement and retained if the average agreement exceeded $r=.23$, which is an empirical estimate of the profile agreement between two randomly paired profiles. For approximately 50 situation descriptions (out of 810 total) a rating with low agreement was dropped and an additional rating was completed. The four ratings were averaged to create a composite, consensual view of the situation.

\section{Results}

Slow-LH scores in this dataset were computed as previously described. The average overall slow-LH score was $.35(S D=.17)$ indicating that on average people have personality trait patterns that better fit the prototypical slow-LH person than the prototypical fast-LH person. The average distinctive slow-LH score was $.00(S D=.14)$, which is a mathematically required value given that the average CAQ profile was statistically removed. Unlike the previous datasets, there was a statistically significant sex difference in overall slow-LH scores, with females $(M=.38, S D=.16)$ scoring higher on slow-LH than males $(M=.32, S D=.17)$, $t(202)=3.06, p=.003$. A similar sex difference was observed for distinctive slow-LH with females $(M=.02, S D=.14)$ scoring higher than males $(M=-.03, S D=.14), t(202)=2.56, p=.011$.

How do slow-life history people behave in their daily lives? The overall and distinctive slow-LH scores for each participant were correlated with the self-reported behavioral composites of the 67-item RBQ. The results are displayed in Table 4. To protect against capitalizing on chance, the randomization test procedure described previously was employed, with the results appearing in the last row of Table 4.

The results in Table 4 are generally consistent with what was found in the two previous studies. Overall slow-LH is associated with a bevy of positive behaviors (e.g., seeming likeable, doing interesting things, liking others), while correlates of overall fast-LH comprise largely a list of negative behaviors (e.g., saying negative things about oneself, expressing insecurity, blaming others, keeping others at a distance). However, the picture is not quite the same when distinctive slow-LH is examined. While distinctive slow-LH is still positively associated with concentrating/working hard at tasks, displaying ambition, being interested in intellectual/ cognitive matters, and expressing agreement, it is also positively associated with behaving in a fearful or timid manner and expressing sympathy. An even more divergent picture emerges when examining the negative correlates of distinctive slow-LH. These suggest that fast-LH people, while still engaging in some negative behaviors (e.g., being condescending, expressing hostility) also engage in a number of adaptive and socially skilled behaviors (e.g., initiating humor, talking, expressing sexual interest, and exhibiting social skill).

Can slow-life history correlates be accounted for by situation selection? While the data in Studies 1 and 2 came from direct observations of behavior in a laboratory setting, the data in
Table 4 came from a study where participants self-reported their behavior in their daily lives. Thus, while the similarity of the results in Table 4 to the results from Studies 1 and 2 seems compelling, it is possible that the slow-LH correlates with the behaviors shown in Table 4 are due, entirely or in part, to situation selection. That is, if persons with slow-LH are more likely to find themselves in particular situations, then these situational factors may drive the behavioral correlates.

To examine this possibility, we first correlated the slow-LH scores for each participant with third party rated composites of the 81-item RSQ (average composites across all 4 situations). This analysis yielded very few statistically significant correlations, and the average absolute correlation was not much more than would be expected by chance, for both overall (mean absolute $r=.06, p=$ .263 ) and distinctive (mean absolute $r=.07, p=.104$ ) slow-LH. These results suggest that LH strategy plays little role in situation selection and thus situation selection could not explain the relationship between slow-life history and behavior. However, to sufficiently rule out this hypothesis we used the situation selection correlations (both overall and distinctive) just described as empirical templates of the kinds of situations in which slow-LH people tend to find themselves. These templates were then correlated with each person's third-party rated RSQ in each situation to create a score indicating the degree to which the person was in a slow-LH selected situation on average. Next, these average situation selection scores were used to predict the 67 average behavioral scores from the RBQ, and the residuals were retained. These residuals represent one's average behavior across four situations after controlling for one's propensity to be in a situation typically selected by a slow-LH person. Lastly, these behavioral residuals were correlated with each person's overall and distinctive slow-LH scores. Thus, these correlations represent the degree to which slow-LH is correlated with self-reported everyday behavior-averaged over four occasions-after controlling for situation selection effects. This set of correlations was correlated $r=.97$ and .90 with the original correlations that appear in Table 4 for overall and distinctive, respectively. These results are a clear indication that situation selection does not account for the behavioral correlates of slow-LH in Table 4. In this context "situation selection" means the self-selection into certain situations (and implicitly out of others) by the individual in developmental time, not the selection acting upon individuals over evolutionary time by the chronic recurrence of certain types of situations and the possible differences in their frequencies of occurrence in different environments that drive life history evolution.

\section{Discussion}

The results of this study largely replicate the findings of Studies 1 and 2. Looking at overall slow-LH only paints a portrait of the slow-LH person as behaving in a generally positive manner, while his or her fast-LH counterpart behaves in a largely negative manner. However, removing normativeness from the measure of $\mathrm{LH}$ yields a more balanced view of both slow-LH and fast-LH persons. These results also extend the findings of Studies 1 and 2 to daily life. However, the design comes with its own set of problems. One is that situation selection may have explained the behavioral correlates of slow-LH (i.e., slow-LH persons could have selected situations that yielded the behaviors reported in Table 4). How- 
ever, such an explanation was safely ruled out by the data. A second issue, and one we alluded to at the beginning of this article, is the use of self-reports (rather than direct observation) of behavior. In this case, we believe that the use of self-reports was a reasonable tradeoff for the gains in ecological validity provided by examining real world situations, especially when considered in conjunction with, and as a complement to, the prior studies that measured directly observed behavior in more artificial settings.

\section{General Discussion}

The primary goal of this research was to better understand the behavioral correlates of individual differences in life history strategy. A secondary goal was to examine how the behavioral correlates of life history may differ when normativeness is removed from the measurement. In doing so, this article examined archival data gathered during three different time periods over 20 years. They included directly observed behaviors from nearly 300 participants in laboratory-induced social interactions, word usage in a 1-hr life history interview, and selfreported behavior from four situations experienced by participants in their daily lives.

Taken as a whole, the data support two general conclusions: (a) People scoring high versus low on slow-life history behave differently from each other and (b) Some of the differences in their behavior might be masked by normativeness. Specifically, if one only examined overall life history (which includes normativeness) it would be easy to conclude that slow-LH is positively associated with a very desirable set of social behaviors and negatively associated with a very undesirable set of social behaviors. However, a different picture emerges when normativeness is taken into account: Both people scoring high and low on slow-life history have a number of qualities that might be considered adaptive (or positive) and maladaptive (or negative). The results paint a picture of the distinctive slow-life history person as one who is kind, considerate, hard-working, and reliable but also as one who is socially inept, insecure, overcontrolling, and shy. At the other end of the spectrum, distinctively fast-life history people come across as talkative, socially skilled, assertive, dominant, charming, and interesting, but also unpredictable, self-indulgent, hostile, moody, manipulative, and undercontrolling.

Further, as evidenced by the results of Study 3, the patterns of behavior associated with life history strategy are not limited to laboratory settings. Particularly striking is that even self-reports of behavior, which can be subject to social desirability biases, were associated with life history strategies in both adaptive and maladaptive ways, contingently upon the nature of the different environments in which they might be expressed. Further, by using statistical control in Study 3 and experimental control in Studies 1 and 2, the behavioral correlates of life-history strategy can be seen to be not merely by-products of situation selection; they appear to transcend context at the individual level.

Individual differences in life history strategy have been interpreted as having been generated and maintained over evolutionary time by a variety of different selective pressures, which are not mutually exclusive (for a more exhaustive treatment of these different evolutionary mechanisms, see Penke, Denisson, \& Miller, 2007). One theory is that of frequency-dependent selection, in which a state of balanced polymorphism among slow and fast life history phenotypes is envisioned within the same population, but the operation of this mechanism presumes that there exists a negative feedback relation among the prevalence of these alternative phenotypes such that a higher fitness outcome for one phenotype is dependent upon a higher relative frequency of the other. Unfortunately, there is currently no available empirical evidence that such a negative feedback relation actually exists for alternative life history strategies in humans. Another model is that of mutation-selection balance, in which positive directional selection for a particular life history strategy (presumably the slower variant) is offset by the rate of deleterious pleiotropic mutations that would chronically degrade the coadapted genome by damaging its genetic underpinnings. Although there is some behavioral-genetic evidence for a certain degree of recent and positive directional selection for slower life histories in humans (Figueredo \& Rushton, 2009), the relative proportion of nonadditive to additive genetic variance in human life history strategy (about $23 \%$ of the total genetic variance, which is about $61 \%$ of the total phenotypic variance), although substantial, would not appear to support the mutation-selection balance model as the primary mechanism for the maintenance of diversity among alternative human life history strategies in the population. Yet another model is based on balancing selection based on environmental heterogeneity, wherein different life history strategies are differentially suited to different microenvironments within the distribution of the population. A modified version of this model, sometimes called the coral reef model (Figueredo \& Jacobs, 2010; Figuerdo, Jacobs, Burger, Gladden, \& Olderbak, 2011; Figueredo, Sefcek, et al., 2005; Figueredo et al., 2010) emphasizes the heterogeneity of the social environment (interactions among conspecifics), as opposed to the external physical ecology or the "community" ecology (biotic interactions among allospecifics), and proposes that sociality generates social microniches to which different personality and life history variants are differentially adapted. This model is generally supported by a review of the animal personality literature (reported in Figueredo, Sefcek, et al., 2005) wherein it was observed that systematic individual differences in behavior were largely associated with sociality across a wide variety of nonhuman animal species.

Even more recent variants on this idea are the cognitive differentiation-integration effort (CD-IE) hypothesis (Woodley, 2011; Woodley, Figueredo, Brown, \& Ross, 2013) and the strategic differentiation-integration effort (SD-IE) hypothesis (Figueredo, Woodley, Brown, \& Ross, in press), which predicts the regulation by life history speed $(K)$ of the magnitudes of the correlations among its components, such that slower life history strategists exhibit less correlated life history traits than faster life history strategists. Thus, slower life history strategists are both cognitively and conatively differentiated with respect to their life history traits because strategic specialization with respect to various domainspecific resource allocations permits resource polymorphism under the conditions of elevated intraspecific social competition characteristic of the higher and more stable population densities of slower life history strategists. This model, based on quantitative theoretical ecology, predicts that centripetal or disruptive selective pressures due to social competition produce intraspecific character displacement and competitive release through socioecological niche-splitting. Substantial empirical support from psychometric 
data has recently been presented in support of both the $C D-I E$ (Woodley et al., 2013) and the SD-IE (Figueredo et al., in press) hypotheses in humans. These integration and differentiation phenomena are presumably driven by the evolutionary dynamics underlying the coral reef model, and constitute empirical tests of the predictions of that theory.

\section{Limitations and Future Considerations}

One particular strength of this research is that it uses three samples gathered at different times over a 20 year period. While all three samples came from the undergraduate population at the same university, the university at which these data were collected has been and is still one of the most ethnically diverse universities in the United States (U.S. News \& World Report, 2012), which may speak to the generalizability of the findings.

The results were rather inconsistent regarding sex differences in both mean levels of slow-LH and the correlates of slow-LH history. Whereas Studies 1 and 2 showed no sex differences in slow-LH scores, Study 3 indicated that women scored higher than men. Further, sex differences in the behavioral correlates in all three studies were inconsistent enough in our view to not merit reporting. Although sex differences in the behavioral correlates of slow-LH may be real, a much larger and perhaps more targeted investigation would be necessary to identify them reliably. To go even further, Sex $\times$ Situation interactive effects may also be present, but an even larger study would be required to identify these reliably. For the time being, it is best to say that while sex differences on slow-LH, both in terms of mean levels and correlates, may exist, a decisive conclusion cannot be drawn from the present data.

\section{Implications}

The results of these studies have several implications for life history theory. First, all three studies reveal a general tendency for people to fall more toward the slow-LH pole of the slow versus fast life history continuum. Indeed, the average overall slow-LH template match was quite consistent across all three studies with match scores of $.35, .36$, and .34 for Studies 1-3, respectively. Such a finding is consistent with prior claims that humans are generally a slow-LH species.

However, there are sizeable individual differences, associated with important behavioral consequences. Interestingly, when the measurement of life history is unconfounded from normativeness, there appear to be two sides to slow-LH and fast-LH strategies. On the positive- or perhaps adaptive-side, individuals who utilize a slow-LH strategy seem to be simply nicer people who are considerate of others, but on the negative side, they are also less sure of themselves and more likely to control their impulses, perhaps to their own detriment. Persons tending more toward fast-LH strategies are socially skilled, charming, and interesting; however, they are also impulsive and self-centered and tend to dominate others. Thus the strengths associated with a slow-LH history strategy appear to be the weaknesses of the fast-LH strategy and vice versa.

These findings underline the importance of disentangling normativeness and psychological adjustment from other psychological constructs. While it may be true that in reality people who are high on slow-LH also tend to be psychologically well-adjusted (Figueredo et al., 2007), there is much to be learned by studying life history separately from adjustment. Unlike previous research, which paints a very negative view of fast-LH strategists, the present analyses demonstrate that when factors that naturally covary with $\mathrm{LH}$ are statistically removed, a slightly different picture of fast-LH strategists emerges. In this view, fast-LH strategists, while still dominating, manipulative, and egocentric, are also more charming and socially skilled. These findings, coupled with the fact that persons on average tend toward slow-LH strategies provide evidence for frequency-dependent theories of trait selection (Buss, 1991, 2009). They are also consistent with suggestions that fast-LH traits may covary with physical symmetry (Holtzman, Augustine, \& Senne, 2011), attractiveness (Holtzman \& Strube, 2010), and narcissism (Holtzman \& Strube, 2011). More generally however, the present research adds to the growing body of literature demonstrating how the interpretation of individual difference constructs may change when normativeness and distinctiveness are taken into account (e.g., Biesanz, West, \& Millevoi, 2007; Klimstra, Hale, Raaijmakers, \& Meeus, 2012; Klimstra et al., 2010; Leary \& Allen, 2011; Sherman et al., 2012).

\section{Conclusion}

Life history theory provides an overarching framework for understanding a wide variety of behavioral differences in styles of mating, parenting, and social interaction. However, the empirical work on individual differences in life history theory has been relatively sparse and largely limited to self-report. This research provides empirical support for life history theory in the form of directly observed behavior and promotes a better understanding of the relative advantages and disadvantages of slow versus fast life history strategies.

\section{References}

Baird, B. M., Le, K., \& Lucas, R. E. (2006). On the nature of intraindividual personality variability: Reliability, validity, and associations with well-being. Journal of Personality and Social Psychology, 90, 512-527. doi:10.1037/0022-3514.90.3.512

Baumeister, R. F., Vohs, K. D., \& Funder, D. C. (2007). Psychology as the science of self-reports and finger movements: Whatever happened to actual behavior? Perspectives on Psychological Science, 2, 396-403. doi:10.1111/j.1745-6916.2007.00051.x

Bem, D. J., \& Funder, D. C. (1978). Predicting more of the people more of the time: Assessing the personality of situations. Psychological Review, 85, 485-501. doi:10.1037/0033-295X.85.6.485

Biesanz, J. C., West, S. G., \& Millevoi, A. (2007). What do you learn about someone over time? The relationships between length of acquaintance and consensus and self-other agreements in judgments of personality. Journal of Personality and Social Psychology, 92, 119-135. doi: 10.1037/0022-3514.92.1.119

Blackman, M. C., \& Funder, D. C. (1996). Self-esteem as viewed from the outside: A peer and gender perspective. Journal of Social Behavior and Personality, 11, 115-126.

Blackman, M. C., \& Funder, D. C. (1998). The effect of information on consensus and accuracy in personality judgment. Journal of Experimental Social Psychology, 34, 164-181. doi:10.1006/jesp.1997.1347

Block, J. (1960). On the number of significant findings to be expected by chance. Psychometrika, 25, 369-380. doi:10.1007/BF02289754 
Block, J. (1978). The Q-sort method in personality assessment and psychiatric research. Palo Alto, CA: Consulting Psychologists Press. (Original work published 1961)

Borkenau, P., \& Zaltauskas, K. (2009). Effects of self-enhancement on agreement in personality profiles. European Journal of Personality, 23, 107-123. doi:10.1002/per.707

Buss, D. М. (1991). Evolutionary personality psychology. Annual Review of Psychology, 42, 459-491. doi:10.1146/annurev.ps.42.020191.002331

Buss, D. M. (2009). How can evolutionary psychology successfully explain personality and individual differences? Perspectives on Psychological Science, 4, 359-366. doi:10.1111/j.1745-6924.2009.01138.x

Cabeza De Baca, T., \& Jordan, A. C. (2012). To know is not to love: Cognitive and affective barriers toward evolution. Personality and Individual Differences, 53, 681-686. doi:10.1016/j.paid.2012.05.015

Charles, K., \& Egan, V. (2005). Mating effort correlates with self-reported delinquency in a normal adolescent sample. Personality and Individual Differences, 38, 1035-1045. doi:10.1016/j.paid.2004.06.021

Craik, K. H., Ware, A. P., Kamp, J., O'Reilly, C., III, Staw, B., \& Zedeck, S. (2002). Explorations of construct validity in a combined managerial and personality assessment programme. Journal of Occupational and Organizational Psychology, 75, 171-193. doi: $10.1348 / 09631790260098758$

Creed, A. T., \& Funder, D. C. (1998a). Social anxiety: From the inside and outside. Personality and Individual Differences, 25, 19-33. doi:10.1016/ S0191-8869(98)00037-3

Creed, A. T., \& Funder, D. C. (1998b). The two faces of private selfconsciousness: Self-report, peer-report, and behavioral correlates. European Journal of Personality, 12, 411-431. doi:10.1002/(SICI)10990984(199811/12)12:6<411::AID-PER317>3.0.CO;2-C

Eaton, L. G., \& Funder, D. C. (2001). Emotional experience in daily life: Valence, variability, and rate of change. Emotion, 1, 413-421. doi: 10.1037/1528-3542.1.4.413

Edwards, A. L. (1957). The social desirability variable in personality assessment and research. New York, NY: Dryden.

Ellis, B. J., Figueredo, A. J., Brumbach, B. H., \& Schlomer, G. L. (2009). Fundamental dimensions of environmental risk: The impact of harsh versus unpredictable environments on the evolution and development of life history strategies. Human Nature, 20, 204-268. doi:10.1007/ s12110-009-9063-7

Fast, L. A., \& Funder, D. C. (2008). Personality as manifest in word use: Correlations with self-report, acquaintance-report, and behavior. Journal of Personality and Social Psychology, 94, 334-346. doi:10.1037/00223514.94.2.334

Fast, L. A., \& Funder, D. C. (2010). Gender differences in the correlates of self-referent word use: Authority, entitlement and depressive symptoms. Journal of Personality, 78, 313-338. doi:10.1111/j.1467-6494.2009 .00617.x

Fast, L. A., Reimer, H. M., \& Funder, D. C. (2008). The social behavior and reputation of the attributionally complex. Journal of Research in Personality, 42, 208-222. doi:10.1016/j.jrp.2007.05.009

Figueredo, A. J., Cabeza de Baca, T., \& Woodley, M. A. (2013). The measurement of human life history strategy. Personality and Individual Differences, 55, 251-255. doi:10.1016/j.paid.2012.04.033

Figueredo, A. J., \& Jacobs, W. J. (2010). Aggression, risk-taking, and alternative life history strategies: The behavioral ecology of social deviance. In M. Frias-Amernta \& V. Corral-Verdugo (Eds.), Bio-psychosocial perspectives on interpersonal violence (pp. 3-28). Hauppauge, NY: Nova Science.

Figueredo, A. J., Jacobs, W. J., Burger, S. B., Gladden, P. R., \& Olderbak, S. G. (2011). The biology of personality. In G. Terzis \& R. Arp (Eds.), Information and living systems: Essays in philosophy of biology (pp. 371-406). Cambridge, MA: MIT Press.

Figueredo, A. J., \& Rushton, J. P. (2009). Evidence for shared genetic dominance between the general factor of personality, mental and phys- ical health, and life history traits. Twin Research and Human Genetics, 12, 555-563. doi:10.1375/twin.12.6.555

Figueredo, A. J., Sefcek, J. A., Vásquez, G., Brumbach, B. H., King, J. E., \& Jacobs, W. J. (2005). Evolutionary personality psychology. In D. M Buss (Ed.), Handbook of evolutionary psychology (pp. 851-877). Hoboken, NJ: Wiley.

Figueredo, A. J., Vásquez, G., Brumbach, B. H., \& Schneider, S. M. R. (2004). The heritability of life history strategy: The K-factor, covitality, and personality. Social Biology, 51, 121-143.

Figueredo, A. J., Vásquez, G., Brumbach, B. H., \& Schneider, S. M. R. (2007). The K-factor, covitality, and personality: A psychometric test of life history theory. Human Nature, 18, 47-73. doi:10.1007/BF02820846

Figueredo, A. J., Vásquez, G., Brumbach, B. H., Sefcek, J. A., Kirsner, B. R., \& Jacobs, W. J. (2005). The K-factor: Individual differences in life history strategy. Personality and Individual Differences, 39, 13491360. doi:10.1016/j.paid.2005.06.009

Figueredo, A. J., Wolf, P. S. A., Gladden, P. R., Olderbak, S. G., Andrzejczak, D. J., \& Jacobs, W. J. (2010). Ecological approaches to personality. In D. M. Buss \& P. H. Hawley (Eds.), The evolution of personality and individual differences (pp. 210-239). New York, NY Oxford University Press.

Figueredo, A. J., Wolf, P. S. A., Olderbak, S. G., Gladden, P. R., Wenner, C., Hill, D., . . Rushton, J. P. (2013). The psychometric assessment of human life history strategy: A Meta-analytic construct validation. Manuscript in preparation.

Figueredo, A. J., Woodley, M. A., Brown, S. D., \& Ross, K. C.. (in press). Multiple successful tests of the strategic differentiation-integration effort (SD-IE) hypothesis. Journal of Social, Evolutionary, and Cultural Psychology.

Fleeson, W., \& Wilt, J. (2010). The relevance of Big Five trait content in behavior to subjective authenticity: Do high levels of within-person behavioral variability undermine or enable authenticity achievement? Journal of Personality, 78, 1353-1382.

Funder, D. C., Furr, R. M., \& Colvin, C. R. (2000). The Riverside Behavioral Q-Sort. A tool for the description of social behavior. Journal of Personality, 68, 451-489. doi:10.1111/1467-6494.00103

Funder, D. C., Kolar, D. W., \& Blackman, M. C. (1995). Agreement among judges of personality: Interpersonal relations, similarity, and acquaintanceship. Journal of Personality and Social Psychology, 69, 656-672. doi:10.1037/0022-3514.69.4.656

Furr, R. M. (2008). A framework for profile similarity: Integrating similarity, normativeness, and distinctiveness. Journal of Personality, 76 1267-1316. doi:10.1111/j.1467-6494.2008.00521.x

Furr, R. M. (2009). Personality as a truly behavioural science. European Journal of Personality, 23, 369-401. doi:10.1002/per.724

Furr, R. M., \& Funder, D. C. (1998). A multimodel analysis of personal negativity. Journal of Personality and Social Psychology, 74, 15801591. doi:10.1037/0022-3514.74.6.1580

Furr, R. M., \& Funder, D. C. (2004). Situational similarity and behavioral consistency: Subjective, objective, variable-centered and personcentered approaches. Journal of Research in Personality, 38, 421-447. doi:10.1016/j.jrp.2003.10.001

Furr, R. M., Wagerman, S., \& Funder, D. C. (2010). Personality as manifest in behavior: Direct behavioral observation using the revised Riverside Behavioral Q-Sort (RBQ-3.0). In C. R. Agnew, D. E. Carlston, W. G. Graziano, \& J. R. Kelly (Eds.), Then a miracle occurs: Focusing on behavior in social psychological theory and research (pp. 186-204). Oxford, England: Oxford University Press.

Gladden, P. R., Figueredo, A. J., \& Jacobs, W. J. (2009). Life history strategy, psychopathic attitudes, personality, and general intelligence. Personality and Individual Differences, 46, 270-275. doi:10.1016/j.paid .2008.10.010 
Gladden, P. R., Sisco, M., \& Figueredo, A. J. (2008). Sexual coercion and life-history strategy. Evolution and Human Behavior, 29, 319-326. doi:10.1016/j.evolhumbehav.2008.03.003

Holtzman, N. S., Augustine, A. A., \& Senne, A. L. (2011). Are pro-social or socially aversive people more physically symmetrical? Symmetry in relation to over 200 personality variables. Journal of Research in Personality, 45, 687-691. doi:10.1016/j.jrp.2011.08.003

Holtzman, N. S., \& Strube, M. J. (2010). Narcissism and attractiveness. Journal of Research in Personality, 44, 133-136. doi:10.1016/j.jrp.2009 .10 .004

Holtzman, N. S., \& Strube, M. J. (2011). The intertwined evolution of narcissism and short-term mating: An emerging hypothesis. In W. K. Campbell \& J. D. Miller (Eds.), The handbook of narcissism and narcissistic personality disorder: Theoretical approaches, empirical findings, and treatments (pp. 210-220). Hoboken, NJ: Wiley.

Kashdan, T. B., Sherman, R. A., Yarbro, J., \& Funder, D. C. (in press). How are curious people viewed and how do they behave in social situations? From the perspectives of self, friends, parents, and unacquainted observers. Journal of Personality.

Klimstra, T. A., Hale, W. W., III, Raaijmakers, Q. A. W., \& Meeus, W. H. J. (2012). Hypermaturity and immaturity of personality profiles in adolescents. European Journal of Personality, 26, 203-211. doi: 10.1002/per.825

Klimstra, T. A., Luyckx, K., Hale, W. W., III, Goossens, L., \& Meeus, W. H. J. (2010). Longitudinal associations between personality profile stability and adjustment in college students: Distinguishing among overall stability, distinctive stability, and within-time normativeness. Journal of Personality, 78, 1163-1184

Leary, M. R., \& Allen, A. B. (2011). Self-presentational persona: Simultaneous management of multiple impressions. Journal of Personality and Social Psychology, 101, 1033-1049. doi:10.1037/a0023884

Letzring, T. D., Block, J., \& Funder, D. C. (2005). Ego-control and ego-resiliency: Generalization of self-report scales based on personality descriptions from acquaintances, clinicians, and the self. Journal of Research in Personality, 39, 395-422. doi:10.1016/j.jrp.2004.06.003

Letzring, T. D., Wells, S. M., \& Funder, D. C. (2006). Quantity and quality of available information affect the realistic accuracy of personality judgment. Journal of Personality and Social Psychology, 91, 111-123. doi:10.1037/0022-3514.91.1.111

MacArthur, R. H., \& Wilson, E. O. (1967). The theory of island biogeography. Princeton, NJ: Princeton University Press.

Markey, P. M., Funder, D. C., \& Ozer, D. J. (2003). Complementarity of interpersonal behaviors in dyadic interactions. Personality and Social Psychology Bulletin, 29, 1082-1090. doi:10.1177/0146167203253474

Naumann, L. P., Guillaume, E. M., \& Funder, D. C. (2012). The correlates of high parental academic expectations: An Asian-Latino comparison. Journal of Cross-Cultural Psychology, 43, 515-520.

Nave, C. S., Sherman, R. A., \& Funder, D. C. (2008). Beyond self-report in the study of hedonic and eudaimonic well-being: Correlations with acquaintance reports, clinician judgments and directly observed behavior. Journal of Research in Personality, 42, 643-659. doi:10.1016/j.jrp 2007.09.001

Olderbak, S. G., \& Figueredo, A. J. (2010). Life history strategy as a longitudinal predict of relationship satisfaction and dissolution. Personality and Individual Differences, 49, 234-239. doi:10.1016/j.paid.2010 .03 .041

Penke, L., Denissen, J. J. A., \& Miller, G. F. (2007). The evolutionary genetics of personality. European Journal of Personality, 21, 549-587. doi:10.1002/per.629

Pennebaker, J. W., Francis, M. E., \& Booth, R. J. (2001). Linguistic inquiry and word count (LIWC): LIWC2001 [Software]. Mahwah, NJ. Erlbaum.

Pianka, E. R. (1970). On $r$ - and K-selection. American Naturalist, 104, 592-596. doi:10.1086/282697
R Core Team. (2013). R: A language and environment for statistical computing [Computer software]. Vienna, Austria: R Foundation for Statistical Computing.http://www.r-project.org/

Reznick, D., Bryant, M. J., \& Bashey, F. (2002). r- and K-selection revisited: The role of population regulation in life-history evolution. Ecology, 83, 1509-1520.

Rowe, D. C. (2000). Environmental and genetic influences on pubertal development: Evolutionary life history traits? In J. L. Rodgers, D. C. Rowe, \& W. B. Miller (Eds.), Genetic influences on human fertility and sexuality (pp. 147-168). Boston, MA: Kluwer. doi:10.1007/978-1-4615 4467-8_10

Rowe, D. C., Vazsonyi, A. T., \& Figueredo, A. J. (1997). Mating effort in adolescence: Conditional or alternative strategy? Personality and Individual Differences, 23, 105-115. doi:10.1016/S0191-8869(97)00005-6

Rushton, J. P. (1985). Differential K theory: The sociobiology of individual and group differences. Personality and Individual Differences, 6, 441452. doi:10.1016/0191-8869(85)90137-0

Rushton, J. P. (2000). Race, evolution, and behavior: A life-history perspective (3rd ed.). Port Huron, MI: Charles Darwin Research Institute

Schimmack, U., Oishi, S., Furr, R. M., \& Funder, D. C. (2004). Personality and life satisfaction: A facet-level analysis. Personality and Social Psychology Bulletin, 30, 1062-1075. doi:10.1177/ 0146167204264292

Sherman, R. A. (2011). Assessing persons, situations, and behavior: Implications for consistency, congruence, and construal. (Unpublished doctoral dissertation). University of California, Riverside.

Sherman, R. A., \& Funder, D. C. (2009). Evaluating studies in personality and behavior: Beyond the number of significant findings to be expected by chance. Journal of Research in Personality, 43, 1053-1063. doi 10.1016/j.jrp.2009.05.010

Sherman, R. A., Nave, C. S., \& Funder, D. C. (2010). Situational similarity and personality predict behavioral consistency. Journal of Personality and Social Psychology, 99, 330-343. doi:10.1037/a0019796

Sherman, R. A., Nave, C. S., \& Funder, D. C. (2012). Properties of persons and situations related to overall and distinctive personality-behavior congruence. Journal of Research in Personality, 46, 87-101. doi: 10.1016/j.jrp.2011.12.006

Sherman, R. A., Nave, C. S., \& Funder, D. C. (2013). Situational construal is related to personality and gender. Journal of Research in Personality, 47, 1-14. doi:10.1016/j.jrp.2012.10.008

Sneed, C. D., McCrae, R. R., \& Funder, D. C. (1998). Lay conceptions of the five-factor model and its indicators. Personality and Social Psychology Bulletin, 24, 115-126. doi:10.1177/0146167298242001

Spain, J. S., Eaton, L. G., \& Funder, D. C. (2000). Perspectives on personality: The relative accuracy of self versus others for the prediction of behavior and emotion. Journal of Personality, 68, 837-867. doi: 10.1111/1467-6494.00118

U.S. News \& World Report. (2012). Campus ethnic diversity. Retrieved from http://colleges.usnews.rankingsandreviews.com/best-colleges/rankings/ national-universities/campus-ethnic-diversity? $\mathrm{src}=$ stats

Vazire, S., \& Funder, D. C. (2006). Impulsivity and the self-defeating behavior of narcissists. Personality and Social Psychology Review, 10, 154-165. doi:10.1207/s15327957pspr1002_4

Wagerman, S. A., \& Funder, D. C. (2007). Acquaintance reports of personality and academic achievement: A case for conscientiousness Journal of Research in Personality, 41, 221-229. doi:10.1016/j.jrp.2006 .03 .001

Wagerman, S. A., \& Funder, D. C. (2009). Situations. In P. J. Corr \& G. Mathews (Eds.), Cambridge handbook of personality (pp. 27-42). Cambridge, England: Cambridge University Press. doi:10.1017/ CBO9780511596544.005 
Wood, D., Gosling, S. D., \& Potter, J. (2007). Normality evaluations and their relation to personality traits and well-being. Journal of Personality and Social Psychology, 93, 861-879. doi:10.1037/0022-3514.93.5.861

Wood, D., \& Wortman, J. (2012). Trait means and desirabilities as artifactual and real sources of differential stability of personality traits. Journal of Personality, 80, 665-701. doi:10.1111/j.1467-6494.2011 .00740.x

Woodley, M. A. (2010). Are high-IQ individuals deficient in common sense? A critical examination of the "clever sillies" hypothesis. Intelligence, 38, 471-480. doi:10.1016/j.intell.2010.06.002

Woodley, M. A. (2011). The cognitive differentiation-integration effort hypothesis: A synthesis between the fitness indicator and life history models of human intelligence. Review of General Psychology, 15, 228245. doi: $10.1037 / \mathrm{a} 0024348$
Woodley, M. A., \& Figueredo, A. J. (2013). Historical variability in heritable general intelligence: Its evolutionary origins and sociocultural consequences. Buckingham, England: University of Buckingham Press.

Woodley, M. A., Figueredo, A. J., Brown, S. D., \& Ross, K. C. (2013). Four successful tests of the cognitive differentiation-integration effort hypothesis. Intelligence. Advance online publication. doi:http://dx.doi .org/10.1016/j.intell.2013.02.002

Received February 7, 2013 Revision received June 4, 2013

Accepted June 19, 2013 